\title{
Gestão ambiental e a política pública de sustentabilidade do Poder Judiciário de Goiás, Brasil
}

\section{Lúcia Christina Rondon Goulart* e Pedro Araújo Pietrafesa}

${ }^{1}$ Pontifícia Universidade Católica de Goiás. Mestrado em Desenvolvimento e Planejamento Territorial. Av. Universitária, 1.440. Setor Universitário. Goiânia-GO, Brasil (CEP 74605-010). E-mail: lunarg30@gmail.com.

Resumo. Este artigo objetivou compreender e analisar o comportamento do Poder Judiciário do Estado de Goiás diante das questões ambientais, e como a política pública em prol da sustentabilidade tem sido implementada na Administração Pública, observando como esta política está interligada às diretrizes da Resolução no 201/2015, do Conselho Nacional de Justiça (CNJ). Neste contexto, insere-se a Educação Ambiental como fundamento de uma gestão ambiental eficiente, correlacionada a temas contemporâneos, que apontam para um ambiente sustentável. Procedeu-se, portanto, a uma análise qualitativa da eficiência e da eficácia da gestão ambiental no âmbito do Poder Judiciário de Goiás. Deste modo, para a consecução deste estudo, foram utilizadas a revisão de literatura e o estudo de caso, com ênfase no Tribunal de Justiça de Goiás (TJ-GO). Na fundamentação teórica, primou-se pelas abordagens gerenciais e estratégicas desenvolvidas pela Administração Pública, amparadas pelas ideias de sustentabilidade, educação ambiental e conscientização humana, tendo em vista a preservação dos recursos naturais e o incentivo a mudanças de hábitos e comportamentos, estimulando atitudes necessárias para a disseminação de uma cultura institucional sustentável mais reflexiva, visando à preservação ambiental justa e equilibrada para as gerações atuais e futuras. Ademais, foram analisados dados referentes ao consumo e às práticas sustentáveis do TJ-GO.

Palavras-chave: Educação ambiental; Gestão pública; Meio ambiente; Sustentabilidade.

Abstract. Environmental management and the public sustainability policy of the Judicial Power of State of Goiás, Brazil. This study aims to analyze the juridical actions promoted by the State of Goiás to increase the development of the environmental education, as the foundation of an efficient environmental management, correlating with contemporary themes that portray the sustainable environment. In this way, to understand as a general objective, the behavior of the Goiás

Recebido $22 / 11 / 2019$

Aceito

$22 / 12 / 2019$

Publicado

$31 / 12 / 2019$

Acesso aberto

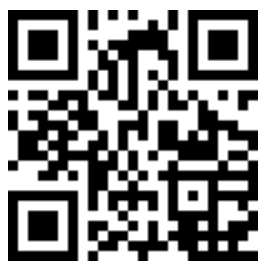

ORCID

(ㄱ) 0000-0002-2318-2834

Lúcia Christina

Rondon Goulart

(D) 0000-0003-0542-4753

Pedro Araújo

Pietrafesa 
judiciary in relation to environmental issues, seeking to analyze how the public policy of sustainability has been implemented in the public administration effectively and efficiently, interconnected with the guidelines punctuated by Resolution $201 / 2015$, of the Brazilian National Council of Justice. As a specific objective, to observe the consumption results and sustainable practices/omissions of the TJGO, through the analysis of the compiled infographics found on the CNJ website, based on the social and environmental thematic axes increased by the sustainable judicial management in Goiás. Therefore, the justification for the development of this research is pertinent, given the absence of studies specifically found in relation to this theme, having an interest in the analysis of the qualitative evaluation of the efficiency developed by the environmental management of the Judiciary in the State of Goiás. The research will be developed through the study of case methodology, with emphasis on the Goiás Court of Justice, having the theoretical basis on the bibliographical review, evidencing the management and strategic approaches developed by the public administration, based on the ideas of sustainability, environmental education and human awareness, in order to safeguard natural resources and encourage the change of habits and behaviors of the citizens, stimulating necessary attitudes for the dissemination of a more reflective sustainable institutional culture, towards the fair and balanced environmental preservation for all generations.

Keywords: Public management; Environmental education; Environment; Sustainability.

\section{Introdução}

A convivência em sociedade requer respeito mútuo entre os cidadãos. Neste contexto, importa mencionar que a existência humana tem sua continuidade associada à necessidade de preservação dos recursos naturais sustentáveis disponíveis. Estes recursos representam um direito de todos, sendo indispensáveis à preservação e à continuidade da própria espécie humana. Diante disso, é urgente que os grupos estruturados em cidades e comunidades reparem às necessidades das gerações vindouras. Estas necessidades estão cada vez mais vinculadas às questões ambientais, imprescindíveis à vida humana.

Nota-se que o tema sustentabilidade é caro ao mundo contemporâneo. Por isso, a importância de ações estratégicas ambientais no contexto da Administração Pública. Estas ações consistem em fundamentos para a criação de meios que visem à manutenção e ao desenvolvimento de procedimentos integrados de gestão e planejamento da máquina pública.

Neste contexto, encontram-se os programas que servem de referência e embasamento de práticas sustentáveis na Administração Pública, como a Agenda Ambiental na Administração Pública (A3P), do Ministério do Meio Ambiente (MMA, 2019), e a Resolução no 201/2015, do Conselho Nacional de Justiça (CNJ, 2015).

A administração pública, enquanto gestora das ações no contexto ambiental, busca aplicar as normatizações que efetivamente se associam às diretrizes das determinações do art. 225, da Carta Magna (Brasil, 1988), tendo como critérios os princípios constitucionais vinculados à gestão 
ambiental pública. Diante disto, alguns destes princípios são abordados neste estudo, em especial o que trata da aplicabilidade das ações de gestão e práticas das políticas públicas criadas com o objetivo de fomentar a preservação ambiental e o seu necessário equilíbrio, e que são empregadas nas atividades rotineiras da Administração Pública judicante.

Observa-se que, diante do estigma ambiental vivenciado no mundo contemporâneo, o incentivo ao processo de desenvolvimento sustentável é fundamental. Deste modo, as instituições públicas devem encampar o protagonismo no exercício das funções administrativas, uma vez que o setor público se apresenta como consumidor expressivo de bens e serviços, efetivando-se como agente motivador para uma efetiva mudança de cultura e hábitos; em especial, no âmbito do Poder Judiciário.

Tendo como base esta premissa, algumas estratégias relacionadas com a preservação ambiental, como as indicadas no programa A3P (MMa, 2019), são apontadas neste estudo. Ressalta-se que este modelo de gestão é usado por vários órgãos públicos em diversas esferas de poder e objetiva implementar ações socioambientais, a fim de contribuir com a redução do desperdício e do gasto público.

0 programa A3P (MMA, 2019) e a Resolução CNJ no 201/2015 (CNJ, 2015) têm como finalidades transmitir conhecimentos e efetivar procedimentos com foco na preservação do meio ambiente e no controle de danos correlatos, incentivando 0 desenvolvimento contínuo de ações sustentáveis. Entende-se que estas ações promovem a conscientização e a Educação Ambiental (EA) entre seus membros e parceiros, haja vista que a gestão ambiental consiste em parte integrante do movimento de desenvolvimento social e humano das instituições públicas.
Deste modo, no âmbito organizacional, as ações de gestão ambiental visam a contribuir com o processo de aprimoramento e integração entre instituição e sociedade, unindo esforços que promovam meios eficientes de preservação dos recursos naturais, além de fomentar práticas eficazes para a implementação de políticas públicas em prol da sustentabilidade e a efetivação dos princípios basilares da Educação Ambiental.

Assim, para o desenvolvimento de uma boa gestão pública ambiental, faz-se necessário o incentivo à Educação Ambiental. Esta proposta objetiva construir conceitos novos, elaborados nos meios sociais e amparados em uma cultura reflexiva, com propostas de valorização do bem comum, sendo concretizadas por meio de ações e comportamentos vividos em entidades públicas.

Com base nestas considerações, o presente artigo aborda, preliminarmente, a Administração Pública. Para tanto, procede-se ao estudo de caso, tendo como foco o Tribunal de Justiça do Estado de Goiás (TJ-GO). Busca-se abranger, de modo genérico, a origem, a conceituação, a estrutura e a organização da Administração Pública, com objetivo de propor ações e práticas que fomentem a preservação ambiental e a sustentabilidade. Busca-se, também, incentivar à EA, como caminho para a mudança de hábitos e costumes de uma cultura institucional, objetivando alcançar uma gestão ambiental eficiente e adequada ao ecossistema e à sociedade.

Além disso, aborda-se a gestão ambiental no Poder Judiciário do Estado de Goiás mediante análise dos resultados contemplados no Plano de Logística Sustentável, compreendendo dados de 2015 a 2018 e mensurando a responsabilidade socioambiental nas unidades judiciárias, conforme orientações contempladas pela Resolução CNJ no 201/2015 (CNJ, 2015). E ainda, procede-se à análise dos 
resultados acerca das ações e práticas desenvolvidas e implementadas, tendo como foco os eixos temáticos Papel, Copo Descartável, Impressão, Água, Telefonia Fixa e Móvel, Energia, Água e Esgoto, Capacitação e Ações de Inclusão. Estes eixos temáticos indicados pela Resolução CNJ no 201/2015 (CNJ, 2015), que objetiva promover o uso e o consumo consciente e racional na instituição, em prol do ecossistema e da sociedade.

Ademais, aborda-se contextualmente a organização e a estruturação da Administração Pública, buscando, em seguida, tratar, brevemente, do desenvolvimento da gestão ambiental no Poder Judiciário de Goiás, com base na ideia de EA no ambiente organizacional, com foco no alcance de um gerenciamento público eficiente e nas diretrizes de conscientização acerca de ações e práticas sustentáveis pela Administração Pública.

Por fim, são apresentados os índices referentes a consumo, gastos e atitudes/omissões da Administração Pública e seus jurisdicionados, no cumprimento e na efetivação da política pública de sustentabilidade, com vistas a uma gestão pública ambiental judiciária eficiente, justa e equilibrada.

\section{Metodologia}

Este artigo foi elaborado com base na constatação da necessidade de uma abordagem sobre a gestão ambiental no âmbito do Poder Judiciário de Goiás, em virtude da ausência de análises específicas sobre este tema. Procedeu-se, assim, a um estudo de caso no TJ-GO. Almejou-se, com isso, verificar o desenvolvimento e a efetividade das ações e práticas sustentáveis no ambiente organizacional promovidas pela Administração Pública e seus jurisdicionados.

Salienta-se a relevância do estudo de caso como método de pesquisa, de modo a exercer papel importante na delimitação do objeto, demonstrando os resultados da prática real sustentável desenvolvida no âmbito do Poder Judiciário de Goiás.

Corroborando este entendimento, Yin (2001) observa que o estudo de caso serve como estratégia empírica de pesquisa, compreendendo um método que abrange abordagens específicas de coletas e análise de dados. Por tratar-se de um assunto amplo e complexo, sua abordagem não é pertinente fora do contexto real onde se dá o fenômeno.

Feitas estas primeiras considerações, pontua-se que a análise dos resultados aferidos e compilados pelos infográficos disponíveis no portal da Internet do CNJ, relacionados com o processo de gestão ambiental do Poder Judiciário do Estado de Goiás, teve como propósito compartilhar com a comunidade acadêmica, a sociedade e com instituições públicas e privadas as consequências das ações e práticas sustentáveis desempenhadas pelo Poder Judiciário de Goiás. Ressalta-se ainda, que foram feitas observações acerca da necessidade do incentivo de mudança de hábitos e comportamentos da corporação, a fim de promover a consciência, a educação e a responsabilidade socioambiental, conforme as orientações dispostas na Resolução CNJ no 201/2015 (CNJ, 2015).

Além disso, buscou-se reunir informações detalhadas e sistemáticas sobre um determinado fenômeno ou assunto (Patton, 2002). Assim sendo, fezse necessário compreender a dinâmica do contexto real, envolvendo a análise profunda e exaustiva de um ou poucos objetos, com o objetivo de conhecê-lo detalhadamente (Gil, 2010).

Os resultados apresentados podem servir de paradigma para outras instituições públicas ressaltando questões sobre o desenvolvimento de gestão e planejamento ambiental, contemplando modelos positivos/ negativos de ações, omissões e práticas sustentáveis a serem realizadas ou evitadas por estas instituições.

Procurou-se o desenvolvimento de uma pesquisa qualitativa, que 
contemplasse a qualidade do objeto analisado, sem fazer uso de instrumentos estatísticos, primando por compreender e apresentar os resultados descritivos da análise, conforme tratado por Stake (2011).

Assim, incluiu-se neste estudo a investigação documental sobre a gestão ambiental do TJ-GO. Como variável independente, a análise da gestão ambiental no Poder Judiciário de Goiás apontou para a necessidade de determinar estratégias eficientes e eficazes destinadas à responsabilidade socioambiental; como variável dependente, apontou para a conveniência da Administração Pública em demarcar as diretrizes da Resolução CNJ no 201/2015 (CNJ, 2015).

Coube, portanto, realizar a análise e a verificação das ações e dos resultados gerados no ambiente organizacional para a efetivação de um meio ambiente sustentável, de modo a promover o desenvolvimento, a educação e a conscientização ambiental, humana e social, com vistas a uma gestão ambiental judiciária estável, duradoura, útil e vantajosa ao ecossistema e à sociedade.

Desta forma, buscou-se elaborar um estudo coeso, bem fundamentado. Para tanto, procedeu-se a coleta, seleção, análise e interpretação de textos encontrados em livros, doutrinas, legislações e periódicos, acessados em publicações impressas e eletrônicas, com na gestão ambiental pública. Importa mencionar as bases eletrônicas consultadas: Scientific Electronic Library Online (SciELO) e Google Acadêmico.

Entende-se que a Administração Pública precisa se comprometer com a promoção, o desenvolvimento e o aprimoramento de instrumentos e procedimentos autossustentáveis direcionados à preservação dos recursos naturais. E ainda, deve implementar a economia sustentável no ambiente organizacional, visto que este modelo de administração configura-se como potencial consumidora de produtos e serviços. Portanto, deve agir como incentivadora do processo de formação da consciência coletiva da política de gestão ambiental.

\section{Administração pública}

A operacionalidade da administração pública pode ser caracterizada como a atividade na qual o administrador não detém poder pleno sobre as variáveis de um sistema. Assim como ocorre no setor privado, a administração do setor público pode ser desenvolvida como uma atividade condicionada às expectativas e aos anseios dos ambientes externo e interno, de forma individual ou coletiva. Deste modo, deve promover a associação de esforços, para atender aos anseios públicos de interesses social e ambiental.

Neste contexto, encontram-se as unidades do judiciário, que também fazem parte desta administração. Portanto, devem atuar com base em estratégias, objetivos e metas que primam pela promoção e satisfação da responsabilidade socioambiental. Como ensina Carvalho (2018), as diretrizes da gestão neste cenário estão vinculadas à administração dos serviços públicos desenvolvidos por servidores e jurisdicionados que atuam no Judiciário, o que abrange os procedimentos de comando e controle, planejamento e execução dos atos de gestão ambiental no desempenho dos serviços públicos.

Com relação ao enfoque econômico, Barbieri (1997, p. 143), pontua que a Administração Pública tem buscado ir além, incentivando a mudança do comportamento das pessoas e organizações, em virtude da interferência das ações humanas no meio ambiente. Nota-se que a Administração Pública tem buscado o controle das ações executadas pelos entes que geram os recursos das unidades federativas, almejando a eficiência nas atividades e nos projetos desenvolvidos.

No âmbito do Poder Judiciário, os paradigmas das políticas públicas de sustentabilidade são normatizados pela Resolução CNJ no 201/2015 (CNJ, 2015), 
amparados e comandados também pelas boas práticas de sustentabilidade desenvolvidas pelo programa $\mathrm{A} 3 \mathrm{P}$ do MMA (2019). Mediante esta agenda, foram estabelecidas as diretrizes de maiores impactos, bem como os resultados e as práticas possivelmente aplicadas como mecanismos para nortear as ações de gestão ambiental, com o intuito de planejar, monitorar e conscientizar a sociedade e os agentes públicos, com relação a temática sustentável pública.

Para Silva (2017), a Administração Pública apresenta em seu contexto histórico os padrões de gestão patrimonialista, burocrático e gerencial. Diante do constante processo evolutivo, compreende-se o destaque e a efetivação da Administração Pública após a década de 1960, libertando-se paulatinamente da escola burocrática weberiana, passando a ganhar contornos gerenciais. À época, a sociedade organizava-se estruturalmente, com o objetivo de resolver as dificuldades cotidianas. As ações estavam voltadas para o aprimoramento e o aparelhamento do Estado, em busca de satisfazer o bem comum público.

De acordo com Schultz (2016), a Administração Pública atua como mecanismo de enfrentamento de desafios e estruturas de gestão, permitindo a abertura de espaço para melhorar os resultados para toda a sociedade.

Neste contexto, ao administrador público atribui-se a responsabilidade de melhor gerir e capacitar o corpo funcional no exercício de suas atividades, identificando necessidades, traçando e implementando planos de ação, coordenando e unificando as ações a serem executadas. 0 objetivo é controlar os processos e procedimentos correlatos, solucionando conflitos e alcançando resultados de interesse coletivo.

Já para Resende (2008), a Administração Pública está associada à amplitude de todo o conjunto de atividades ordenadas previamente para a realização dos serviços, com a finalidade de atender às demandas da sociedade, com vistas à satisfação dos interesses sociais coletivos de um modo geral.

Considerada como um processo que engloba um conjunto de ações, impostas legalmente para serem cumpridas por instituições públicas e por pessoas jurídicas, com direitos e deveres no exercício da função administrativa, a Administração Pública pode ser analisada como atividade sólida e imediata que o Estado exerce para garantir o atendimento aos interesses coletivos.

Segundo Daft (2014), as organizações públicas são constituídas de características próprias, sendo coordenadas como entidades sociais com estrutura própria, que possuem metas previamente constituídas para serem alcançadas. As organizações exercem atividades de forma deliberada, associando seu exercício aos interesses da sociedade. No Brasil, a estrutura administrativa federativa compreende as entidades públicas delimitadas de acordo com as esferas federais, estaduais e regionais as quais estiverem inseridas.

Neste sentido, Santos (2005), esclarece que esta estruturação administrativa é disposta conforme as esferas de poder e contribuem para auxiliar na implementação das políticas de sustentabilidade, ao descentralizar a gestão administrativa de cada órgão, com a criação de novos padrões que permitam conscientizar os cidadãos quanto à importância da responsabilidade socioambiental. Isso faz com que as questões propostas sejam eficientemente desempenhadas, com controle e fiscalização da organização administrativa e resultados eficazes.

Corroborando a este entendimento, cabe ressaltar as considerações de Justen Filho (2014), destacando que a descentralização serve como propósito de manter o equilíbrio econômico, organizacional e funcional dos entes federativos, seguindo os princípios constitucionais da administração pública 
para o alcance da efetividade, da eficiência e da eficácia. Neste sentido, o administrador passa a ser visto como agente responsável por gerir a máquina estatal, estando condicionado a orientar, monitorar e controlar as atividades administrativas das unidades da federação que ele representa. Com base nisso, cabe ao agente público a realização do planejamento, direção, acompanhamento e controle dos processos e procedimentos relacionados com as estratégias delineadas para o órgão da unidade federativa correspondente.

\section{Consciência e educação ambiental (EA)}

Observa-se que a Administração Pública do Poder Judiciário de Goiás tem demonstrado timidez quanto à preservação do meio ambiente e à conscientização de ações e práticas sustentáveis. Diante disso, é notória a importância da realização contínua de debates para a revisão nos hábitos e costumes dos sujeitos.

Neste sentido, a EA, enquanto despertar de um novo olhar, não se limita à conquista ou ao domínio da natureza como outrora. Esta educação deve basear-se em uma perspectiva holística, relacionando homem, natureza e universo, e isso deve ser contemplado como política pública de gestão ambiental, com ações e metas definidas.

Assim, para a implementação e a efetivação de uma boa gestão ambiental pública, faz-se necessário o investimento em programas de capacitação e educação ambiental, direcionados aos agentes públicos, de modo a promover a revisão e a mudança de hábitos e costumes arraigados culturalmente. Este é um dos caminhos para alcançar os resultados pretendidos no planejamento estratégico, levando ao êxito organizacional.

Para Gama et al. (2012), a política de gestão ambiental dos órgãos estatais compreende a necessidade de realização de um processo de educação ambiental. Assim, é urgente o trato solidário para com as vertentes ambientais dos espaços sociais, a fim de promover uma verdadeira transformação e mudança cultural.

Neste contexto, inserem-se os planos de gestão ambiental da administração do Poder Judiciário, vinculados aos aspectos educacionais, implementados mediante ações estratégicas das políticas públicas em prol da sustentabilidade e direcionadas à responsabilidade socioambiental institucional.

Há de se ressaltar a abordagem de Reis (2010), acerca das questões que giram em torno das implantações estratégicas. Estas questões englobam as dimensões políticas, econômicas, sociais, tecnológicas e ambientais, e têm como fundamento organizacional a busca por novos meios sustentáveis.

Sabe-se que conscientizar os seres humanos não é tarefa fácil, mas o tempo urge e a natureza grita por socorro. Neste sentido, a EA configura-se como um aspecto indispensável para a regulamentação de práticas sustentáveis tanto individuais quanto coletivas, visando ao controle e à redução de danos ambientais, em benefício ao desenvolvimento de uma boa gestão ambiental. Portanto, a EA acompanha as práticas sociais com base em estratégias de conscientização e de formação de uma nova cultura direcionada à preservação dos recursos naturais, com revisões de comportamentos e práticas sociais que possam interferir na construção de um espaço comum saudável.

Como ressalta Souza (2009), é imprescindível estabilizar continuamente a relação homem-natureza. Assim, devese cuidar para que as ações humanas cotidianas não gerem a degradação do ecossistema, as políticas públicas de gestão ambiental precisam fomentar a cultura social responsável por meio de ações de educação ambiental.

Assim, é oportuno salientar as considerações de Costa (2013), sobre como a Educação Ambiental pode ser tratada como uma forma estratégica de 
orientar as pessoas dos mais diversos espaços sociais com relação à necessidade de promover ações sustentáveis em seu dia a dia. Para Silva et al. (2012), esta ideia é ratificada com a observação dos espaços urbanos e sua interligação com os diversos problemas apresentados no meio ambiente, o que gera a necessidade de debater e propor ações de controle que incentivem as demandas de sustentabilidade, visando ao equilíbrio dos recursos naturais no planeta.

Por sua vez, para Fernandes (2010), as atitudes dos indivíduos podem demonstrar falta de responsabilidade social, podendo estar associada à desinformação, o que demanda conscientização. Desta forma, educação e meio ambiente relacionam-se no contexto da busca pela cidadania, de enfrentando de desafios e necessidades emergentes comuns de um determinado ambiente. Esta relação visa à construção de novos conhecimentos em relação aos processos sociais, de forma a provocar uma reflexão sobre os riscos ambientais oriundos tanto das ações quanto das omissões dos seres humanos.

Ao abordarem a questão ambiental, Alcântara et al. (2012) amparam-se no art. 225, da Constituição Federal de 1988 (Brasil, 1988), para tratar que todos os indivíduos são detentores de direitos relacionados com o equilíbrio ecológico. Sendo assim, cabe ao Poder Público e a todos os cidadãos a obrigação de promover a necessária e indispensável preservação ambiental. Portanto, pode-se afirmar que a EA está intimamente relacionada com 0 desenvolvimento humano e social de determinada comunidade.

Observa-se que a representação socioambiental está caracterizada nas sociedades contemporâneas sob uma perspectiva globalizante, envolvendo o espaço comum. Desta forma, cabe ao Estado e à sociedade como um todo realizarem ações de EA, a fim de conscientizarem os cidadãos sobre os riscos provocados pelas práticas de poluição ambiental.

Neste contexto, importa mencionar as formas de gestão na Administração Pública acerca do controle para o equilíbrio dos recursos ambientais e do monitoramento das ações para evitar ou diminuir os prejuízos causados ao meio comum, com o objetivo de estabelecer condições viáveis de preservação da qualidade de vida e continuidade da espécie humana.

Deste modo, de acordo com Gerhardt e Almeida (2005), as discussões sobre meio ambiente são provenientes da degradação dos recursos naturais pelo homem no decorrer dos anos. Neste sentido, os serviços de EA devem ser tomados como tarefa fundamental, com foco nas questões socioambientais de sustentabilidade e na preservação dos recursos naturais. Objetiva-se, com isso, contribuir para a conservação da biodiversidade, a autorrealização individual e comunitária e a autogestão política e econômica. Enfim, estes processos educativos visam a promover a melhoria nas gestões, no meio ambiente e na qualidade de vida.

\section{Gestão ambiental no judiciário}

A gestão ambiental praticada pelo Poder Judiciário do Estado de Goiás tem como fundamento as recomendações da Resolução CNJ no 201/2015 (CNJ, 2015). Esta orientação tem como meta viabilizar o gerenciamento ambiental sustentável em unidades e núcleos socioambientais judiciários do país.

Por meio da apresentação dos resultados encontrados no portal da Internet do CNJ, objetiva-se apresentar os dados condizentes com a proposta de responsabilidade socioambiental e sustentabilidade implementada e praticada pelo Poder Judiciário. Os dados encontram-se publicados e discriminados no portal da Internet do CNJ. Os resultados tratam das ações e práticas desenvolvidas institucionalmente, com vistas ao alcance da 
responsabilidade socioambiental pelas unidades judiciárias goianas, em cumprimento à Resolução CNJ $\mathrm{n}^{\underline{0}}$ 201/2015 (CNJ, 2015).

Como pontua Oliveira (2012), as escassas publicações acadêmicas sobre a temática da gestão ambiental no âmbito do Poder Judiciário evidenciam a relevância da abordagem, visto que os administradores públicos são capazes de contribuir para uma mudança de cultura e hábitos organizacionais, mediante $\mathrm{o}$ desenvolvimento do processo de responsabilidade, conscientização e educação socioambiental. Esta ação contribuiria tanto para a melhoria da qualidade de vida quanto para a preservação do meio ambiente.

Desta forma, cabe aos administradores e gestores institucionais esclarecerem seus membros, independentemente das atividades que exercem, sobre a função social do Judiciário e a relação deste com a preservação do meio ambiente, em consonância com os métodos de gestão, as condutas e normatizações que prezam pelas boas práticas sustentáveis da Administração Pública.

\section{o Poder Judiciário de Goiás}

Tendo como objeto de estudo o Tribunal de Justiça do Estado de Goiás, é oportuno realizar uma breve contextualização acerca desta unidade de justiça, que foi instalada em $1^{\mathrm{o}}$ de maio de 1874. Atualmente, o TJ-GO possui uma estrutura funcional que abrange 12.289 pessoas, incluindo servidores, colaboradores, estagiários e magistrados, e 41 desembargadores, distribuídos nas 129 Comarcas das unidades judiciárias e administrativas da instituição.

Ao ratificar a sustentabilidade na Administração Pública, o CNJ, por meio da Resolução CNJ no 201/2015 (CNJ, 2015), procurou incentivar e amadurecer a visão ambiental, disseminando orientações e recomendações a serem inseridas no planejamento estratégico do Poder Judiciário, por meio da implantação de unidades e núcleos socioambientais, visando à implementação do Plano de Logística Sustentável.

Neste sentido, os dados apresentados evidenciam as deliberações do TJ-GO frente aos eixos temáticos dispostos na Resolução CNJ no 201/2015 (CNJ, 2015), que englobam os seguintes itens de consumo: Papel, Copo Descartável, Impressão, Água, Telefonia Fixa e Móvel, Energia, Água e Esgoto, Capacitação e Ações de Inclusão. Com isso, intenta-se promover o uso e o consumo consciente e racional, com a otimização de recursos e custos para a instituição e para o ecossistema com base na Educação Ambiental.

Assim, mediante os dados levantados e os resultados encontrados, procura-se evidenciar como o Poder Judiciário do Estado de Goiás, por meio das atividades rotineiras desenvolvidas pelo seu corpo funcional, trata as questões socioambientais de uso, consumo e custos em seu ambiente organizacional. 0 período compreendido para análise foi de 2015 a 2018, a fim de retratar os efeitos do Plano de Logística Sustentável 2017/2019.

Entende-se que cabe às instituições públicas contribuírem para a harmonização dos propósitos almejados, com adaptação do modo de produção e uma manutenção sustentável do meio ambiente, com a criação e implementação de estratégias que viabilizem o controle do gasto público e o redirecionamento das práticas ambientais sustentáveis (Redin e Silveira, 2012).

\section{Resultados e discussão}

Com o objetivo de evidenciar a importância da política pública de sustentabilidade e a conscientização ambiental, bem como o investimento e a propagação da Educação Ambiental na cultura organizacional, direcionada a uma gestão ambiental efetiva, expõe-se, a seguir, os resultados referentes ao consumo, ações e práticas sustentáveis 
positivas e negativas no âmbito do Poder Judiciário do Estado de Goiás.

Os dados mostram, perfunctóriamente, a repercussão dos dispêndios públicos disponibilizados, face aos eixos temáticos abordados pelo judiciário goiano, no período de 2015 a 2018, aferidos conforme os indicadores presentes na Resolução CNJ no 201/2015 (CNJ, 2015).

Com relação ao consumo de resmas de papel, conforme os números apresentados, verifica-se que não houve a diminuição no consumo de papel pelo Poder Judiciário, não alcançando a Meta 01, "Reduzir 10\% do consumo total de papel branco (A4)", do Plano de Logística Sustentável 2017/2019.

A Figura 1 demonstra o consumo de papel realizado na instituição, constatando a evolução progressiva da demanda. Resta evidenciado, um aumento significativo apresentado no ano de 2017, o que não restou justificado pela entidade nenhum fato que amparasse tal gasto.

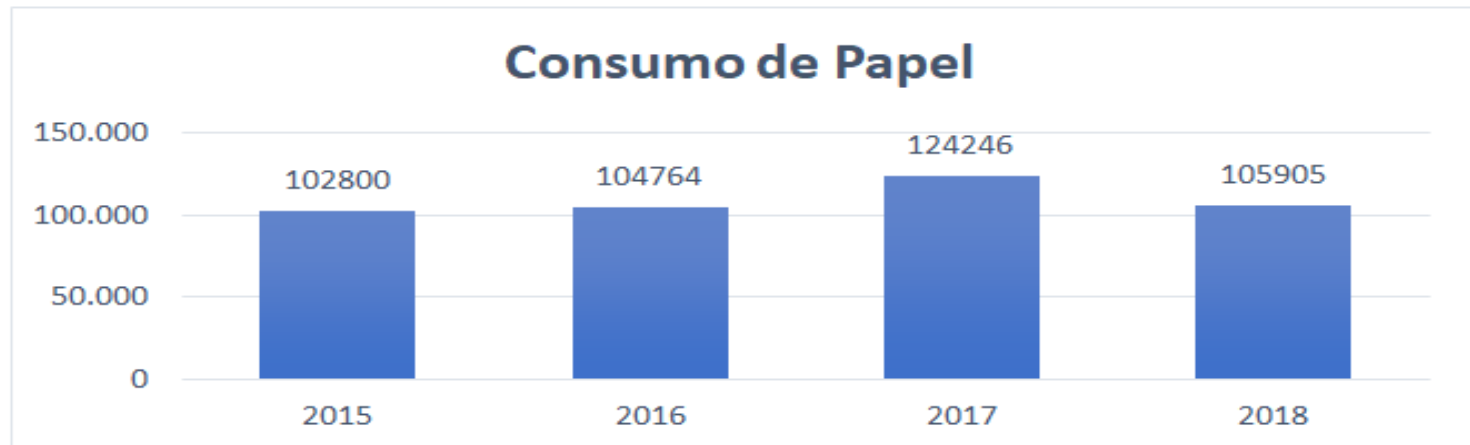

Figura 1. Consumo de papel realizado no Poder Judiciário do Estado de Goiás, entre 2015 a 2018.

Deste modo, o consumo de papel acima demonstrado não se justifica, haja vista a implementação do Processo Judicial Eletrônico nas unidades judiciárias e administrativas do Poder Judiciário, com a digitalização dos autos físicos, transformando-os em virtuais, o que, consequentemente, levaria à diminuição do consumo.

Outro item de consumo a ser destacado é o Copo Descartável, tanto para água quanto para café. Todos estes dados na seguinte ordem: água e café. Observa-se que não houve redução no consumo destes itens, o que configura o desacordo com a Meta 02, "Reduzir 5\% do consumo de copos descartáveis", do Plano de Logística Sustentável 2017/2019.

$\mathrm{Na}$ Figura 2, percebe-se um aumento considerável de copos descartáveis de água e café, entre os anos de 2016 e 2017, permanecendo o progressivo consumo em 2018.

Logo, no que tange à perspectiva de uso e consumo consciente e racional e à garantia dos direitos de cidadania e meio ambiente ecologicamente equilibrado, os números apresentados não satisfazem a perspectiva da economicidade, eficiência e consciência ambiental institucional. Neste sentido, seria oportuno a distribuição de canecas, evitando, desta forma o uso de copos descartáveis, bem como a promoção de campanhas, eventos e palestras com temas ambientais, de modo a despertar e a consolidar os fundamentos da Educação Ambiental na gênese da cultura institucional, princípio basilar para uma gestão ambiental eficiente, dado que uma administração voltada para resultados depende do engajamento de todos os membros de uma determinada instituição. 


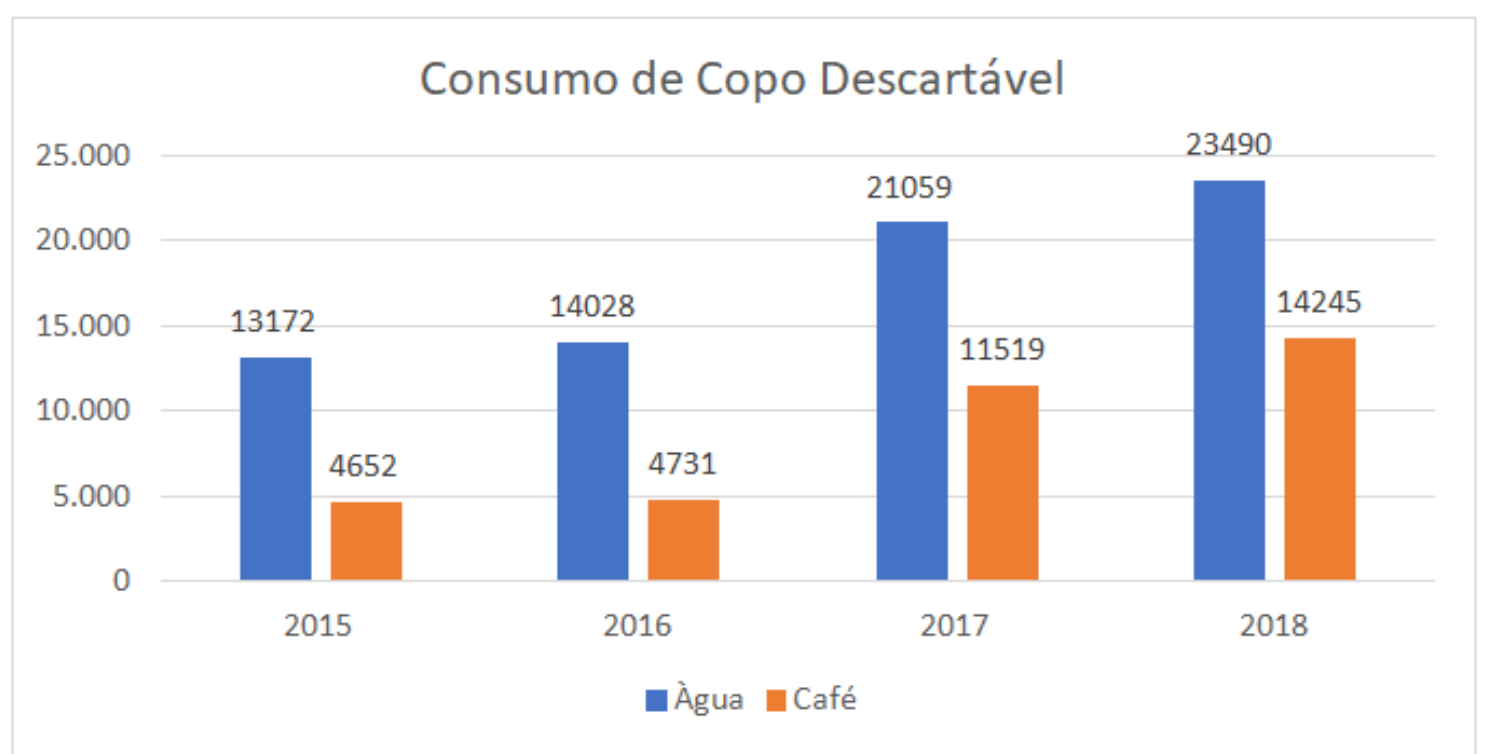

Figura 2. Consumo de copos descartáveis de água e café no Poder Judiciário do Estado de Goiás, entre 2015 a 2018.

No tocante ao item impressão, que faz parte da atividade rotineira da prestação jurisdicional, verificou-se que, em 2015, foram 671.840 unidades de impressão, sendo 4.540 unidades de equipamento; em 2016, as impressões foram zeradas, e o total de equipamentos foi de 13.800 unidades; em 2017, a quantidade de impressão manteve-se zerada, com o quantitativo de 11.500 unidades de equipamentos de impressão; e, em 2018, a quantidade de impressões continuou zerada, com 7.345 unidades de equipamentos de impressão.

Com base nos números apresentados, pode-se afirmar que a implantação do Processo Judicial Digital e do Processo Administrativo Digital teve repercussão positiva, visto que o quantitativo de impressão zerou a partir de 2016, e o número de equipamentos diminuiu. Deste modo, a Meta 03, "Executar 05 ações para melhorar a eficiência na gestão das impressões no âmbito do Poder Judiciário goiano", do Plano de Logística Sustentável 2017/2019, foi atingida, fomentando a melhoria, a efetividade e a sensibilização da administração.

Nota-se que houve um aumento de consumo de descartável de água mineral. Diante disso, faz-se necessária a utilização de outros meios para o consumo de água, como a implantação de filtros purificadores e de bebedouros nas unidades. Somam-se a isso, ações preventivas e educativas de consciência ambiental com relação ao uso, consumo e compromisso sustentável. Cabe também, por parte da administração, a análise da viabilidade de substituição do descartável mediante a adoção de práticas ecoeficientes, com o objetivo de promover melhoria contínua na gestão dos processos de trabalho.

$\mathrm{Na}$ Figura 3 evidencia-se um aumento acentuado no consumo de água envasada retornável nos anos de 2017 e 2018. Já com relação ao dispêndio de descartável de água, houve uma linearidade de gasto, tendo o ápice da sustentabilidade em 2018, com o quantitativo de consumo zerado. 


\section{Água Envasada}

80.000

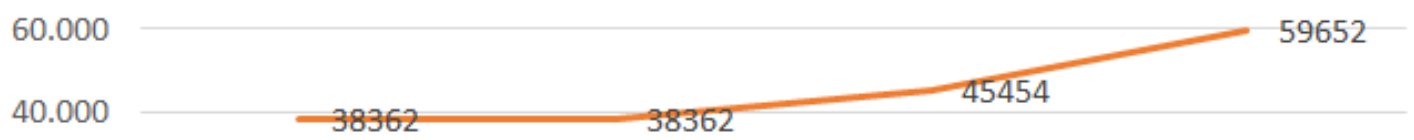

20.000

0

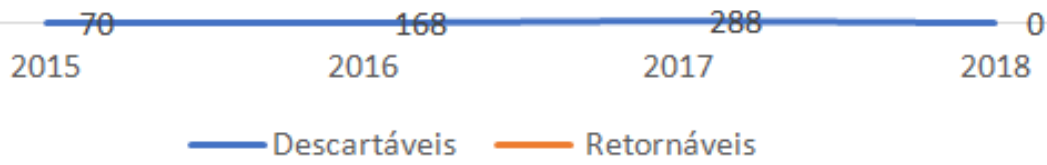

Figura 3. Consumo com embalagens descartáveis e retornáveis de água envasada no Poder Judiciário do Estado de Goiás, entre 2015 a 2018.

Sobre 0 item de consumo telefonia, em 2015 foram gastos $\mathrm{R} \$ 1.054 .098$ (um milhão, cinquenta e quatro mil e noventa e oito reais) com telefonia fixa e R\$ 117.159 (cento e dezessete mil e cento e cinquenta e nove reais) com telefonia móvel; em 2016, R \$ 1.093.839 (um milhão, noventa e três mil e oitocentos e trinta e nove reais) e $\mathrm{R} \$ 223.954$ (duzentos e vinte e três mil, novecentos e cinquenta e quatro reais), respectivamente; em 2017, $\mathrm{R} \$ 872.753$ (oitocentos e setenta e dois mil e setecentos e cinquenta e três reais) e $\mathrm{R} \$ 173.045$ (cento e setenta e três mil, quarenta e cinco reais), na mesma ordem; e, em 2018, R\$ 754.516 (setecentos e cinquenta e quatro mil, quinhentos e dezesseis reais) e $\mathrm{R} \$ 162.145$ (cento e sessenta e dois mil e cento e quarenta e cinco reais), também nesta ordem.

Observa-se que houve redução no consumo com telefonia (fixa e móvel) no período de 2015 e 2018 no cenário institucional. Infere-se que isso seja resultado do advento da implantação do monitoramento e restrições de ligações disponíveis a todos os ramais, tendo uma central telefônica. A despeito disso, muitos esforços devem ser empregados para a racionalização do gasto público e o fomento de ações e práticas sustentáveis na Administração Pública.

Verifica-se o aumento de gasto com energia elétrica, com acréscimo progressivo no período de 2015 a 2018 (Figura 4). Este aumento no consumo deve-se, provavelmente, à implantação da virtualização processual, tendo em vista o aumento no número de computadores utilizados. Estando em dissenso com a Meta 04, "Executar 04 ações visando a combater o desperdício de energia elétrica", do Plano de Logística Sustentável 2017/2019.

Deste modo, cabe à administração propor medidas e ações para viabilizar: controle de consumo de energia nas unidades, medidas socioeducativas que fomentem a consciência e as boas práticas ambientais, por exemplo, o desenvolvimento de projetos de substituição luminária por lâmpadas de LED e a implantação do sistema automático de ligamento $\mathrm{e}$ desligamento de iluminação. 


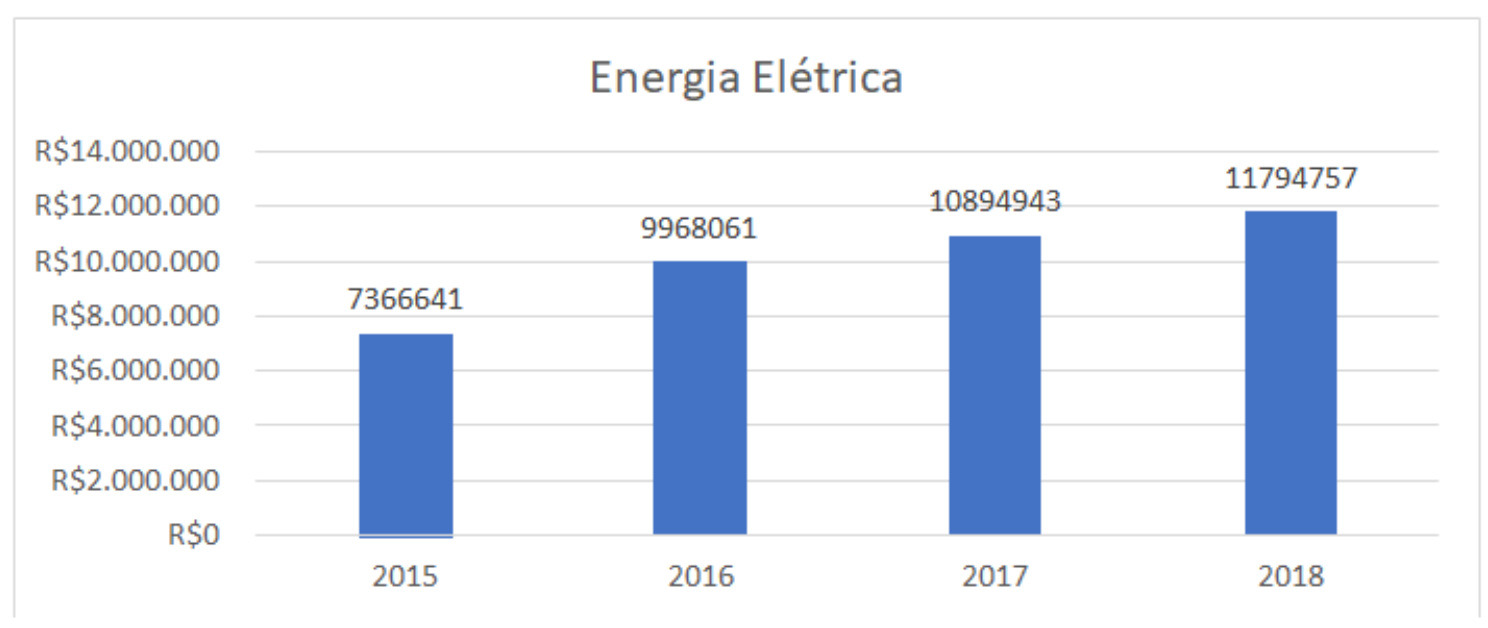

Figura 4. Consumo de energia elétrica no Poder Judiciário do Estado de Goiás, entre 2015 a 2018.

Ressalta-se ainda que as edificações e as estruturas físicas das unidades judiciais e administrativas não são adaptadas com energia solar fotovoltaica, o que poderia contribuir para a diminuição do consumo energético.

Com relação ao gasto com água e esgoto, em 2015 a quantia foi de $\mathrm{R} \$ 1.981 .900$ (um milhão, novecentos e oitenta e um mil e novecentos reais); em 2016, atingiu a importância de $\mathrm{R} \$$ 2.627.627 (dois milhões, seiscentos e vinte e sete mil e seiscentos e vinte e sete reais); em 2017, foi de $\mathrm{R} \$ 2.992 .431$ (dois milhões, novecentos e noventa e dois mil e quatrocentos e trinta e um reais); e, em 2018, o valor foi de $\mathrm{R} \$ 2.841 .648$ (dois milhões, oitocentos e quarenta e um mil e seiscentos e quarenta e oito reais).

Acerca deste gasto, importa mencionar o desacordo e o descumprimento da Meta 05, "Executar 04 ações visando a combater o desperdício de água", do Plano de Logística Sustentável 2017/2019. Percebe-se que muitas unidades judiciárias de Goiás não são adaptadas com torneiras temporizadoras e as descargas não são ecoeficientes. Além disso, muitas instituições não fazem a coleta de água das chuvas para reuso em jardinagem ou na limpeza. Estas ações, se implantadas, contribuiriam para a diminuição do consumo.

Posto isso, nota-se que, mediante análise dos gastos no âmbito do Poder Judiciário no período de 2015 a 2018, houve aumento de custos; consequentemente, aumentou o consumo de recursos naturais em um momento que exige economia na utilização dos insumos e a promoção do consumo sustentável. Desta forma, é necessário rever conceitos, mudar padrões e comportamentos, por meio da construção de um compromisso mais efetivo com o desenvolvimento sustentável.

Outro aspecto a ser destacado diz respeito à consolidação das políticas públicas em prol da sustentabilidade, por meio do Plano de Logística Sustentável, implementado pela Resolução CNJ $\mathrm{n}^{\underline{0}}$ $201 / 2015$, que trata da qualidade de vida no trabalho, com ações voltadas para o aperfeiçoamento da gestão, alinhado aos valores e objetivos estratégicos institucional.

Observa-se que, em 2015, não foi realizada nenhuma ação de inclusão e de qualidade de vida, sendo realizadas apenas 1 (uma) ação solidária e 1 (uma) ação de capacitação e sensibilização. Em 2016, progressos foram observados. Naquele ano procedeu-se às seguintes ações: 1 (uma) de inclusão, 1 (uma) de 
capacitação e sensibilização, 6 (seis) solidárias e 12 (doze) ações de qualidade de vida. 0 ano 2017, por sua vez, foi marcado pelo crescimento do número de ações, a saber: 1 (uma) de inclusão, 6 (seis) de capacitação e sensibilização, 10 (dez) solidárias e 14 (catorze) ações de qualidade de vida. Por fim, em 2018, constatou-se que não houve avanços significativos das ações, com números similares aos do ano anterior: 1 (uma) ação de inclusão, 6 (seis) de capacitação e sensibilização, 10 (dez) solidárias e 8 (oito) ações de qualidade de vida, com cumprimento da Meta 11, "Promover 08 ações voltada para a solidariedade $e$ inclusão social", do Plano de Logística Sustentável 2017/2019.

Com base no exposto, pode-se afirmar que a sustentabilidade engloba as dimensões sociais, culturais, ambientais e econômicas. Assim sendo, não há como falar em mudança de cultura e hábitos, se não houver $o$ incentivo à qualidade de vida no ambiente de trabalho e à capacitação. Estes fatores são primordiais para uma gestão eficiente, que contemple aspectos como inclusão, ressocialização e colaboração solidária coletiva.

Sabe-se que o caminho trilhado pela Educação Ambiental é árduo; tem pedras. Contudo, é preciso seguir. A humanidade não aceita mais o caos que o próprio homem provocou mediante seu desrespeito com a natureza. Chegou-se num ponto em que se fazem necessárias ações em prol de um mundo melhor.

Neste sentido, o Judiciário, como órgão que leva a justiça a quem precisa, necessita interiorizar a justiça ambiental (posicionamento efetivo dos tomadores de decisão, revisão da cultura institucional, conscientização do corpo funcional, reavaliação do clima organizacional), revendo planejamentos, conceitos, estratégias, missões e objetivos, e eliminando os impedimentos quanto à promoção de uma gestão ambiental sustentável.

\section{Considerações finais}

Com base na abordagem proposta por este estudo, poucos avanços referentes à gestão ambiental foram constatados na Administração Pública do Poder Judiciário de Goiás. Nota-se que se fazem necessários ao Judiciário de Goiás fundamentos sólidos sobre educação e conscientização ambiental, para que o planejamento, o controle e a fiscalização com relação à matéria sustentável estejam mais presentes nas ações e práticas rotineiras da organização.

Desta forma, verifica-se a urgência de a instituição direcionar seu olhar para a construção e a fundamentação de programas educacionais de instrução, prevenção e conscientização, e que estes sejam disseminados entre os tomadores de decisões, os agentes públicos e todos os cidadãos. Há também a necessidade premente de desenvolvimento, criação e implementação de ações estratégicas que orientem o corpo funcional quanto à mudança de hábitos, a fim de promover uma transformação na cultura do órgão, fomentando a consciência no ambiente de trabalho e na sociedade, estimulando a realização de práticas sociais responsáveis, ambientalmente justas e equilibradas.

Neste sentido, ao gestor público cumpre papel fundamental e deve desempenhar com excelência as habilidades de planejar, executar e controlar. Assim, ele deve implementar mecanismos que permitam transmitir conhecimentos às pessoas e promover capacitação, a fim de formar cidadãos com princípios e valores fundamentados na sustentabilidade ambiental, social e humana, pois o espaço comum é um ambiente compartilhado. Portanto, coletivo, o que exige ações responsáveis.

Neste contexto, e com vistas à sustentabilidade, a EA age no clima organizacional, configurando-se como caminho que possibilita a interação 
social e a busca pela harmonia entre os seres humanos e o meio ambiente. Além disso, a EA visa a promover atitudes de respeito do homem para com a natureza e do homem para com o próprio homem.

Com base no exposto, entende-se que se faz necessário, por parte do Poder Judiciário de Goiás, o investimento na gestão socioambiental nas unidades judiciárias e administrativas (sensibilização e capacitação do corpo funcional), por meio do incentivo de práticas, atitudes e comportamentos que fortaleçam o compromisso em alcançar metas sustentáveis. assevera-se que este caminho é contínuo, solidário, colaborativo, participativo, preventivo, racional e consciente. Ademais, isto é o que se espera do Poder Judiciário: concretizar a justiça com retidão social e ambiental, com vistas à promoção de um ambiente saudável para as gerações presente e futuras.

\section{Conflito de interesses}

Os autores declaram não haver conflito de interesses.

\section{Referências}

Alcântara, L. A.; Silva, M. C. A.; Nishijima, T. Educação ambiental e os sistemas de gestão ambiental no desafio do desenvolvimento sustentável. Revista Eletrônica em Gestão e Tecnologia Ambiental, v. 5, n. 5, p. 734-740, 2012. https://doi.org/10.5902/2236117 04198

Barbieri, J. C. Políticas públicas indutoras de inovações tecnológicas ambientalmente saudáveis. Revista de Administração Pública, v. 31, n. 2, p. 135-152, 1997.

Brasil. Constituição da República Federativa do Brasil de 1988. Disponível em: <http://www.planalto.gov.br/ccivil_03/ constituicao/ConstituicaoCompilado.htm>. Acesso em: 5 jul. 2019.

Carvalho, M. Manual de Direito Administrativo. 5. ed. rev., atual. e ampl. São Paulo: JusPODVM, 2018.
CNJ - Conselho Nacional de Justiça. Justiça em Números 2018: ano base 2017. Brasília: CNJ, 2018. Disponível em: $<$ https://www.cnj.jus.br/files/conteudo/arq uivo/2018/08/44b7368ec6f888b383f6c3de 40c32167.pdf>. Acesso em: 5 jul. 2019.

CNJ-Conselho Nacional de Justiça. Resolução no 201, de 03 de março de 2015. Dispõe sobre a criação e competências das unidades ou núcleos socioambientais nos órgãos e conselhos do Poder Judiciário e implantação do respectivo Plano de Logística Sustentável (PLS-PJ). Disponível em: $<$ https://atos.cnj.jus.br/atos/detalhar/atosnormativos?documento $=2126>$. Acesso em: 5 jul. 2019.

Costa, H. K. M.; Simões, A. F.; Santos, E. M.; Beck, R. T. Reflexão sobre o conceito de sustentabilidade e a proposição de sua integralidade. Integrating Cleaner Production Into Sustainability Strategies, v. 22, n. 24, p. 1-10, 2013. Disponível em: $<\mathrm{http}: / /$ www.advancesincleanerproduction.n et/fourth/files/sessoes/6A/6/costa_hkm_et_ al_work.pdf>. Acesso em: 5 jul. 2019.

Daft, R. L. Organizações: teoria e projetos. 11. ed. São Paulo: Cengage Learning, 2014.

Fernandes, D. N. A importância da educação ambiental na construção da cidadania. OKARA: Geografia em Debate, v. 4, n. 1/2, p. 77-84, 2010. Disponível em: <http://www.periodicos.ufpb.br/index.php/ okara/article/download/9129/6951>.

Acesso em: 5 jul.2019.

Gama, S. V. G.; Carvalho, D. T.; Carvalho Júnior, R. P. Geografia, planejamento ambiental e educação ambiental: entre os parâmetros legais e as práticas reais. Geo UERJ, v. 14-23, n. 2, p. 524-551, 2012. https://doi.org/ 10.12957/geouerj.2012.4817

Gerhardt, C. H.; Almeida, J. A dialética dos campos sociais na interpretação da problemática ambiental: uma análise crítica a partir de diferentes leituras sobre os problemas ambientais. Ambiente \& Sociedade, v. 8, n. 2, p. 53-84, 2005. https://doi.org/10.1590/S1414-753X2005 000200004

Gil, A.C. Como elaborar projetos de pesquisa. 5. ed. São Paulo: Atlas, 2010. 
Justen Filho, M. Curso de Direito Administrativo. 10. ed. São Paulo: Revista dos Tribunais, 2014.

MMA - Ministério do Meio Ambiente. Portal A3P. 2019. Disponível em: <http://a3p.mma.gov.br/>. Acesso em: 5 jul.2019.

Oliveira, F. L. (Org.). Justiça em Foco: estudos empíricos. 1. ed. Rio de Janeiro: Editora FGV, 2012.

Patton, M. G. Qualitative research and evaluation methods. 3. ed. Thousand Oaks, CA: Sage, 2002.

Redin, E.; Silveira, P. R. C. Política Ambiental Brasileira: limitações e desafios. Cadernos de Pesquisa Interdisciplinar em Ciências Humanas, v. 13, n. 103, p. 163-188, 2012. https://doi.org/10.5007/1984-8951.2012 v13n103p163

Reis, L. B. Energia, recursos naturais e a prática do desenvolvimento sustentável. São Paulo: Manole, 2012.

Resende, L. Gestão ambiental no Poder Judiciário. Rio de Janeiro: FGV, 2008. (Monografia de especialização em Direito).

Santos, M. A questão do meio ambiente: desafios para a construção de uma perspectiva transdisciplinar. GeoTextos, v. 1, n. 1 , p. $139-151,2005$. https://doi.org/ 10.9771/1984-5537geo.v1i1.3033

Schultz, G. Introdução à gestão de organizações. 1. ed. Porto Alegre: UFRGS, 2016 (Série Ensino, Aprendizagem e Tecnologias). Disponível em: <http://www.ufrgs.br/cursopgdr/downloads Serie/derad103.pdf>. Acesso em: 22 jun. 2019.
Silva, A. S.; Souza, J. G.; Leal, A. C. A Sustentabilidade e suas dimensões como fundamento da qualidade de vida. GeoAtos Revista Geografia em Atos, v. 1, n. 12, p. 2242, 2012. https://doi.org/10.35416/geoatos. v1i12.1724

Silva, T. A. Conceitos e evolução da administração pública: o desenvolvimento do papel administrativo. Anais do VIII Seminário Internacional Sobre Desenvolvimento Regional: Territórios, Redes e Desenvolvimento Regional, 2017. Disponível em: <https://online.unisc.br/acadnet/anais/ index.php/sidr/article/view/16678/4429>. Acesso em: 29 jun.2019.

Souza, M. A. A. Meio ambiente e desenvolvimento sustentável: as metáforas do capitalismo. Cronos, v. 10, n. 2 p. 101-117, $2009 . \quad$ Disponível em: $<$ https://periodicos.ufrn.br/cronos/article/v iew/3289>. Acesso em: 29 jun.2019.

Stake, R. E. Pesquisa qualitativa: estudando como as coisas funcionam. Porto Alegre: Penso, 2011.

Yin, R. K. Estudo de caso: planejamento e métodos. 2. ed. Porto Alegre: Bookmam, 2001.

Informação da Licença: Este é um artigo Open Access distribuído sob os termos da Licença Creative Commons Attribution, que permite uso irrestrito, distribuição e reprodução em qualquer meio, desde que a obra original seja devidamente citada. 